\title{
Can Harmonisation of Fire Resistance Furnaces be Achieved by Plate Thermometer Control?
}

GORDON M. E. COOKE

Fire Research Station

Borehamwood, Herts WD6 2BL, UK

\section{SUMMARY}

Fire resistance furnaces need to be harmonised so that differences in thermal severity are minimised. An economical option is to retain existing furnaces and change the combustion gas temperature sensors used to control the furnace from conventional thermocouples to plate thermometers, so that a more realistic ratio of convective to radiative heat transfer is measured. Results are presented for nine tests involving two gas-fired furnaces in the United Kingdom and one oil-fire furnace in Germany. The tests were made in full size floor furnaces using a purpose-made rig which formed a well insulated roof to the furnace and from which a number of thermocoupled uninsulated stainless steel calibration plate and rod elements were suspended in the combustion gases. Comparisons of the temperature-time profiles for these elements were made when controlling the furnace with conventional thermocouples as standard practice or when controlling using plate thermometers. The tests showed that plate thermometer control markedly reduced differences in the thermal severity of the three furnaces near their centre but showed little advantage when the calibration element temperature-time profiles were averaged over the whole plan area of the furnace.

Keywords: Harmonisation, furnace, thermal severity, plate thermometer, fire resistance.

\section{INTRODUCTION}

A major problem currently facing those engaged in the work of ISO, CEN and other bodies trying to produce harmonised standards for fire resistance tests is the belief that a test specimen tested in one furnace can and often will achieve a different result (ie a different period of fire resistance) when tested in another furnace. There have been suggestions that all the furnaces should be demolished and replaced with new 
standardised furnaces or that a system of correction factors should be applied to test results. These considerations are beyond the scope of this paper.

The main purpose of this paper is to present data on comparative heating rates of socalled calibration elements exposed in different furnaces controlled using conventional thermocouples or plate thermometers. A brief discussion of heat flux in furnaces and the concept of the plate thermometer is therefore appropriate and follows.

The primary modes of heat transfer in a furnace are by radiation and convection, the former being affected inter alia by the emissivity of the furnace gases and the emissivity and temperature of the furnace lining, the latter by turbulence. Unfortunately the heat transfer to a specimen, such as a floor or wall, may be different in different furnaces depending upon the design of the furnace (eg size and shape of furnace, number and location of burners, and the thermal insulation of the furnace linings) and the fuel used (eg oil or gas), and this can markedly affect the thermal severity.

When a fire resistance test is conducted according to ISO 834 [1], the combustion gas temperatures are measured by conventional thermocouples at several positions in the furnace, and their average temperature is made to follow a standard temperature-time curve by adjusting the fuel supply.

Accepting that the thermal response of a test specimen depends on the heat flux imposed on its exposed faces and that the dominant components of heat flux are convective and radiative heat transfer, it is important to use a sensor that, so far as is practical, senses the correct ratio of these two components. When compared with the dimensions and shape of a sensor, the specimen, such as a floor or roof, can be said to have a flat face, and it is therefore important that the sensor measures the correct ratio of convective and radiative heat transfer for a flat surface. The conventional thermocouple does not satisfy this requirement because the tip of the thermocouple is either spherical if the thermocouple employs an exposed bead, or is hemispherical if it is of the Inconel sheathed type. It therefore senses more convective heat transfer than it should.

Babrauskas (USA) [2] and Wickström (Sweden) [3] have suggested that an improved design of thermocouple for furnace control, which senses a higher ratio of radiative to convective heat transfer than is possible with the conventional thermocouple, should incorporate a thin steel plate roughly $100 \mathrm{~mm}$ square - hence the name plate thermometer - with a fast response thermocouple attached to the centre of the unexposed face.

A suitable measuring device, ie the plate thermometer, should:

- have a large surface area to simulate the heat transfer received by the test specimen. Hence the plate thermometer employs a steel plate sensor nominally $100 \mathrm{~mm}$ square,

- have a small thermal inertia so that it can respond quickly to rapid changes in furnace heating conditions. The plate thermometer is made of thin, typically $0.7 \mathrm{~mm}$ thick, Inconel steel sheet with a fast response thermocouple attached to the centre of its unexposed face, 
- have a 'black' surface (ie a highly emissive surface) to simulate radiative heat transfer conditions. The plate thermometer has its surface roughened and then heat treated in an oxygen-rich furnace to attain a high value of emissivity which can be relied upon not to change during repeated testing,

- have its sensor facing away from the test specimen so that the thermal properties of the latter has no influence. The plate thermometer is insulated on the rear face with a layer of ceramic insulation material.

Details of a plate thermometer developed by Statens Provningsanstalt (SP) - The Swedish National Testing Institute - Boräs, Sweden is given elsewhere [3]. A number of fire test laboratories have gained experience with the Swedish design of plate thermometer, and its efficacy has been evaluated in tests [4] in European (UK, German, French and Italian) wall furnaces funded by CEC DGXII Community Bureau of Reference (BCR).

The author proposed that an experimental evaluation of heat transfer rates in floor furnaces was needed and the Construction Directorate of the Department of the Environment UK agreed to sponsor tests in two gas-fired UK furnaces and one oil-fired German furnace. The tests were carried out in 1992.

\section{CONCEPT OF TESTS}

One way to compare the thermal severities of two furnaces A and B is to place a piece of steel, called a calibration element in this paper, in the combustion gases, and measure its rate of heating in each of four exposures: an exposure using plate thermometer control and an exposure using conventional thermocouple control in furnace $A$ and then similarly for furnace B. If the temperature-time profiles of the calibration element are closer together when using plate thermometers than when using conventional thermocouples then this is direct proof that plate thermometer control reduces the difference in the thermal severity of the two furnaces.

There are three provisos:

- The accuracy of furnace control is approximately the same in all the tests.

- The thermal properties, especially the emissivity, of the calibration element does not change between tests.

- The thermal properties of the furnace enclosure do not change between tests.

To assess whether or not the first proviso (accuracy of furnace control) is met the average temperature of the conventional thermocouples and the average temperature of the plate thermometers are plotted against the standard curve. Hence it is possible by eye to assess the accuracy of control. Another way is to measure the difference between the area under the actual temperature-time curve (the control curve) and the standard temperature-time curve and represent this as a percentage for different heating periods, Figure 1. This method is used in ISO 834 and in BS 476: Part 20: 1987 [5] for the periods 0 to 10 minutes, 10 to 30 minutes, and from 30 minutes to the end of test. 
The second proviso can be achieved by ensuring that the calibration element is of an appropriate grade of heat resisting stainless steel which has been specially prepared. The surface is roughened by a particle blasting process and then exposed to at least two high temperature exposures in an oxygen-rich furnace so as to produce a stable oxide layer of unchanging surface emissivity.

The third proviso can be achieved by using a 'roof' on the furnace - the test rig in this work - whose thermal inertia does not change during and between tests.

The results of the tests should be presented graphically so that an assessment can easily be made of a) accuracy of furnace control, and b) comparison of the temperature-time profiles for the same calibration element(s) in different tests.

\section{THE EXPERIMENTAL PROGRAMME}

A programme of nine furnace tests was successfully undertaken - four in the Warrington Fire Research Centre (WFRC) furnace, UK, two in the Loss Prevention Council (LPC) furnace, UK, and three in the Institut für Baustoffe, Massivbau und Brandschutz (IBMB) furnace in Braunschweig, FRG. Two different fire exposure regimes were used - the ISO 834 [I] which simulates a cellulosic fire, and the NPD [6] which represents a hydrocarbon fire of greater initial and overall severity than the ISO 834 fire. Table 1 gives details of the test conditions. Table 2 gives details of the furnace characteristics.

There were three principal objectives:

(i) To compare the temperature-time profiles of identical calibration elements exposed in different furnaces when the furnace was first controlled using plate thermometers and then controlled using conventional thermocouples.

(ii) To compare the heating rates of identical calibration elements at different horizontal and vertical positions within the furnace. This would indicate how uniform the heat flux was throughout the furnace.

(iii) To obtain comparative data on the total heat generated/fuel consumed in the furnace. This was derived in the IBMB tests from measurements of oil consumption, and in the IBMB and LPC tests from measurements of inlet and outlet water temperatures for water flowing through a copper tube immersed in the furnace gases.

Because of the large amount of data collected (data from more than 100 thermocouples and more than 40 calibration elements) it is not possible to provide all of the comparisons in this paper. Only objectives (i) and (ii) are addressed here. 


\section{THE TEST APPARATUS}

\section{The test frame}

The test rig comprised a $4 \mathrm{~m}$ square steel frame made in two parts to facilitate ease of handling and transport by lorry. The frame was designed to rest on the top of each floor furnace and was heavily insulated against fire on its lower face. The insulation comprised $100 \mathrm{~mm}$ Rockwool blanket underdrawn with two layers of $25 \mathrm{~mm}$ thick ceramic fibre blanket. The triple layer of insulation was supported from below with a layer of heat resisting stainless steel mesh. The fire-exposed dimensions were $4 \mathrm{~m} \times 3$ $\mathrm{m}$ for the WFRC furnace and $4 \mathrm{~m} \times 4 \mathrm{~m}$ for the LPC and IBMB furnaces. The frame was used to suspend the calibration elements in the furnace gases below, and locate and support the plate thermometers and conventional thermocouples, Figures 2 and 3.

\section{Calibration elements}

Five calibration plate elements, each $350 \mathrm{~mm}$ square, were mounted in refractory concrete panels which were bolted onto the steel frame with the exposed steel plate level with the lower face of the concrete panels and frame insulation. The calibration plate elements were kindly loaned by SP, Borås. They had been used previously in a number of European and Nordic furnace calibration trials and their surface emissivities had reached steady state conditions.

Each calibration plate element was made up of heat treated $5 \mathrm{~mm}$ thick stainless steel plate (the fire exposed plate), a $2 \mathrm{~mm}$ thick mild steel plate (the unexposed plate) and a $40 \mathrm{~mm}$ thick core made up of two $20 \mathrm{~mm}$ layers of low density ceramic fibre board. The exposed and unexposed steel plates each had 2 thermocouples, each $1 \mathrm{~mm}$ diameter Inconel sheathed, welded near the centre of the hidden faces. Further details are given elsewhere [7]. Only the exposed face temperature data are reported here.

\section{Plate thermometers}

Of the 8 plate thermometers used, 4 were mounted horizontally with their exposed faces viewing the furnace and located near 3 of the calibration plate elements, Figures 2 and 3 , and were used for controlling the furnace for the plate control tests. They were fabricated by FRS and other specialist contractors to recommendations given by SP. The details are shown in Figure 4.

Each plate thermometer was made from $0.7 \mathrm{~mm}$ thick Inconel sheet (grade 600), folded to form a channel section with an exposed face $100 \mathrm{~mm}$ square which was then bead blasted over the whole of the exposed face. A $1.0 \mathrm{~mm}$ diameter mineral insulated Inconel sheathed Type $\mathrm{K}$ thermocouple with a $1.6 \mathrm{~mm}$ diameter bead tip was carefully spot welded to the centre of the unexposed face by The Welding Institute at Abingdon. The thermocouple was additionally trapped in position using a small Inconel steel strip spot welded to the unexposed face of the plate roughly $15 \mathrm{~mm}$ away from the hot junction. 


\section{Conventional thermocouples used for furnace control}

ISO 834 specifies that there should be at least one thermocouple for every $1.5 \mathrm{~m}^{2}$ of surface area of wall or floor with a total number of thermocouples not less than 5 . Two kinds of thermocouple can be used for measuring the furnace combustion gas temperature:

(i) bare wire thermocouples of wire diameter not less than $0.75 \mathrm{~mm}$ and not more than $1.5 \mathrm{~mm}$ placed in a heat resistant tube such as porcelain such that the hot junction is approximately $25 \mathrm{~mm}$ away from the end of the tube, or

(ii) sheathed thermocouples provided they have a sensitivity not less than, and a time constant not greater than, those of bare wire thermocouples.

The thermocouples used in the 3 test laboratories met the ISO recommendations.

\section{EXPERLMENTAL RESULTS}

Although many calibration elements were used (34 in the WFRC tests and 44 in the LPC and IBMB tests) only some of the temperature-time profiles for the calibration plate elements are presented here. A comprehensive report of the tests which also employed calibration rods and spheres is available [8].

At the request of SP the five calibration plate elements were removed after one hour exposure to the ISO 834 fire exposure and were not used in the more severe NPD fire exposure.

Typical combustion gas temperature-time profiles for ISO 834 and NPD fire exposure tests are shown in Figures 5 and 6 respectively. Figure 5 demonstrates that at any point in time the average temperature of the 4 plate thermometers (represented by the non-control curve in Test 2) is always lower than the average temperature of the 5 conventional thermocouples (the control curve) and this reflects the slower response of the plate thermometer. Figure 6 demonstrates the difficulty in following the standard curve using plate thermometers. In all of the tests the control accuracy was well within the deviation permitted by ISO 834, Figure 1.

Figures 7 to 10 are typical comparisons of the average rates of heating of the 5 calibration plate elements. Averages were used so as to represent the average heat flux for the whole plan area of the furnace. Plate thermometer control only slightly reduced the difference in thermal severity between the furnaces: compare Figures 7 with 8 , and 9 with 10 .

However when the temperature-time profiles for the central calibration plate element were compared, plate thermometer control appeared to be very beneficial ie it led to a large reduction in the difference in thermal severity between furnaces: compare Figures 11 with 12 , and 13 with 14 . 
Similar conclusions were reached from a comparison of the temperature-time profiles for the calibration rods reported elsewhere [8]. This was not surprising since the comparisons were made using the same tests and the rods differed from the plates only in terms of their greater mass and slower rate of heating.

\section{CONCLUSIONS}

(i) Plate thermometer control only marginally improved the agreement between different furnaces when the average temperature-time profiles of the five calibration plate elements was used for the comparison. However, plate thermometer control substantially improved the agreement when the temperature-time profile of the central calibration plate element was compared.

(ii) The German (IBMB) oil-fired furnace was thermally more severe than its UK gasfired counterparts (LPC and WFRC).

\section{ACKNOWLEDGEMENTS}

C Crown copyright 1994, Building Research Establishment.

\section{REFERENCES}

1. International Standards Organisation, ISO 834, Fire-resistance tests - elements of building construction, 1975 plus Amendments.

2. Babrauskas V, Standardising control of fire test furnaces, Private Communication, October 1992.

3. Wickström U, The plate thermometer - a simple instrument for reaching harmonised fire resistance tests, NORDTEST project 609-86, Swedish National Testing Institute, Borås, 1988.

4. Ohlsson S, Calibration of fire resistance furnaces with plate thermometers, Commission of the European Communities Report EUR 14555 EN, Brussels, 1993.

5. British Standards Institution. BS 476 Fire tests on building materials and structures, Part 20, Method for determination of the fire resistance of elements of construction (general principles), BSI, 1987.

6. Norwegian Petroleum Directorate, Regulations for Production and Auxiliary Systems on Production Installations, 1978.

7. Sterner E and Wickström U. Calibration of fire resistance test furnaces, NORDTEST project 785-88, Swedish National Testing Institute, Borås 1989.

8. Cooke G M E, Use of plate thermometers for standardising fire resistance furnaces. BRE Occasional Paper, February 1994. 
TABLE 1. Summary of test conditions for the nine tests

\begin{tabular}{|c|c|c|c|c|}
\hline $\begin{array}{l}\text { Test } \\
\text { No. }\end{array}$ & $\begin{array}{l}\text { Laboratory } \\
\text { Designation }\end{array}$ & $\begin{array}{l}\text { Furnace } \\
\text { Control }^{(\mathfrak{l})}\end{array}$ & Exposure & $\begin{array}{c}\text { Test duration } \\
\text { (hours) }\end{array}$ \\
\hline 1 & WFRC & Plate & ISO 834 & 2 \\
\hline 2 & WFRC & Conv & ISO 834 & 2 \\
\hline 3 & WFRC ${ }^{(2)}$ & Plate & NPD & 1 \\
\hline 4 & WFRC ${ }^{(2)}$ & Conv & NPD & 1 \\
\hline 5 & LPC & Conv & ISO 834 & 2 \\
\hline 6 & LPC & Plate & ISO 834 & 2 \\
\hline 7 & IBMB & Plate & ISO 834 & 2 \\
\hline 8 & IBMB & Conv & ISO 834 & 2 \\
\hline 9 & $\mathrm{IBMB}^{(3)}$ & Plate & NPD & 1 \\
\hline
\end{tabular}

NOTES: (1) Plate $=$ Average of temperatures of 4 plate thermometers; Conv = Average of temperatures of 5 conventional thermocouples (2) Funace floor insulated (3) Furnace walls insulated

TABLE 2. Details of Furnace Characteristics

\begin{tabular}{|c|c|c|c|c|}
\hline Characteristic & WFRC & LPC & IBMB & Unit \\
\hline Fuel & Natural gas & Natural gas & Oil & - \\
\hline Number of burners & 14 & 20 & 6 (ISO 834), 7 (NPD) & - \\
\hline Location of burners & 7 per side wall & 10 per side wall & $\begin{array}{l}3 \text { in each side wall } \\
1 \text { in one end wall (NPD only) }\end{array}$ & - \\
\hline $\begin{array}{l}\text { Distance from centre line } \\
\text { of bumers to roof }+\end{array}$ & 950 & 1050 & 700 & $\mathrm{~mm}$ \\
\hline $\begin{array}{l}\text { Position of pressure } \\
\text { measuring point }+\end{array}$ & $100 \mathrm{~mm}$ below soffit & $100 \mathrm{~mm}$ below soffit & $100 \mathrm{~mm}$ below soffit & - \\
\hline $\begin{array}{l}\text { Combustion chamber } \\
\text { size }(1 \times \mathrm{x} \times \mathrm{d})+\end{array}$ & $\begin{array}{l}4 \times 3.5 \times 1.9 \text { (ISO } 834) \\
4 \times 3.5 \times 1.45 \text { (NPD) }\end{array}$ & $4 \times 4 \times 1.850$ & $\begin{array}{l}4 \times 4 \times 1.7 \text { (ISO 834) } \\
4 \times 4 \times 1.65 \text { (NPD) }\end{array}$ & $\mathrm{m}$ \\
\hline $\begin{array}{l}\text { Location of combustion } \\
\text { gas exhaust }\end{array}$ & $\begin{array}{l}4 \text { outlets in one end wall } \\
5 \text { outlets in other end wall }\end{array}$ & Duct in centre of floor & Duct along centre of floor & - \\
\hline Furnace linings & Fire brick for all walls & Fire brick for all walls & $\begin{array}{l}\text { Refractory concrete (side walls) } \\
\text { Aerated concrete (end walls) }\end{array}$ & - \\
\hline Density of linings & 880 for all walls & 880 for all walls & Not known & $\mathrm{kg} / \mathrm{m}^{3}$ \\
\hline $\begin{array}{l}\text { Thermal conductivity of } \\
\text { linings }\end{array}$ & 0.325 for walls* & 0.325 for walls* & Not known & $\mathrm{W} / \mathrm{m}^{\circ} \mathrm{K}$ \\
\hline Heat capacity of linings & 1080 for walls $\theta$ & 1080 for walls $\theta$ & Not known & $\mathrm{J} / \mathrm{kg}^{\circ} \mathrm{K}$ \\
\hline $\begin{array}{l}\text { Additional furnace lining } \\
\text { insulation (only for NPD } \\
\text { exposure) }\end{array}$ & $\begin{array}{l}50 \mathrm{~mm} \text { ceramic fibre blanket } \\
\text { on } 25 \mathrm{~mm} \text { insulation board } \\
\text { with } 600 \mathrm{~mm} \text { air gap below }\end{array}$ & $\begin{array}{l}\text { Not used. No NPD } \\
\text { exposure used in tests) }\end{array}$ & $\begin{array}{l}75 \mathrm{~mm} \text { mineral wool mat on } \\
\text { walls, } 50 \mathrm{~mm} \text { mineral wool } \\
\text { board on floor. No air gaps. }\end{array}$ & - \\
\hline
\end{tabular}

For these tests, but may be different in routine fire resistance tests

Average between $200-1000^{\circ} \mathrm{C}$.

$\ominus \quad$ Average between $0-1500^{\circ} \mathrm{C}$. 


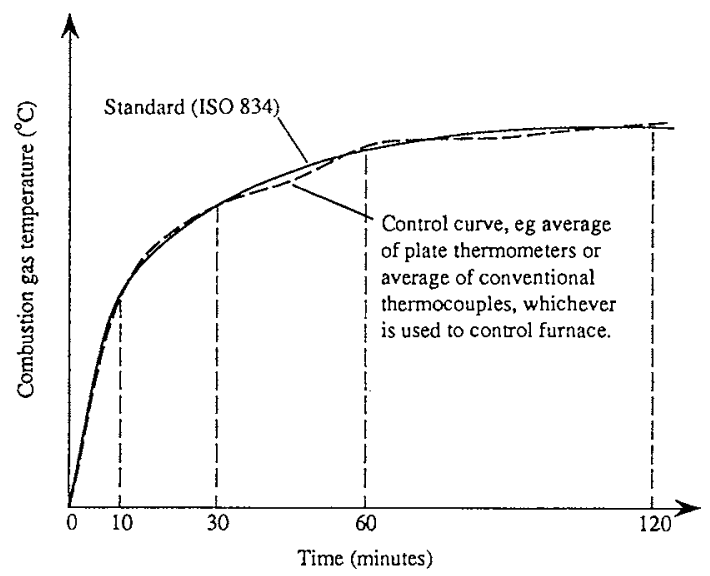

If $A=$ area under control curve and

$\mathrm{B}=$ area under standard curve

then deviation from standard curve is expressed as

$\frac{A-B}{B} \times 100$ and this should not exceed

$15 \%$ from 0 to 10 minutes

$10 \%$ from 10 to 30 minutes

$5 \%$ from 30 to 120 minutes

according to ISO $834: 1975$ (clause 4.1.3.1) and

BS 476: Part 20: 1987 (clause 3.1.2)

Figure 1 Criteria for acceptable deviacion of control curve from standard curve

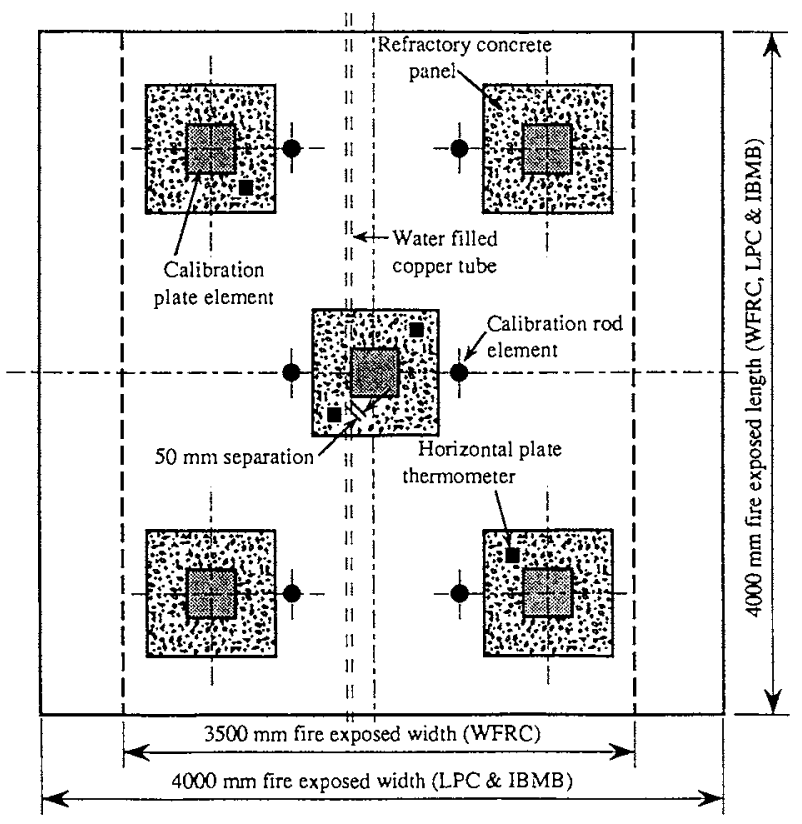

Figure 2 Plan view of test rig showing positions of plate thermometers and calibration elements 


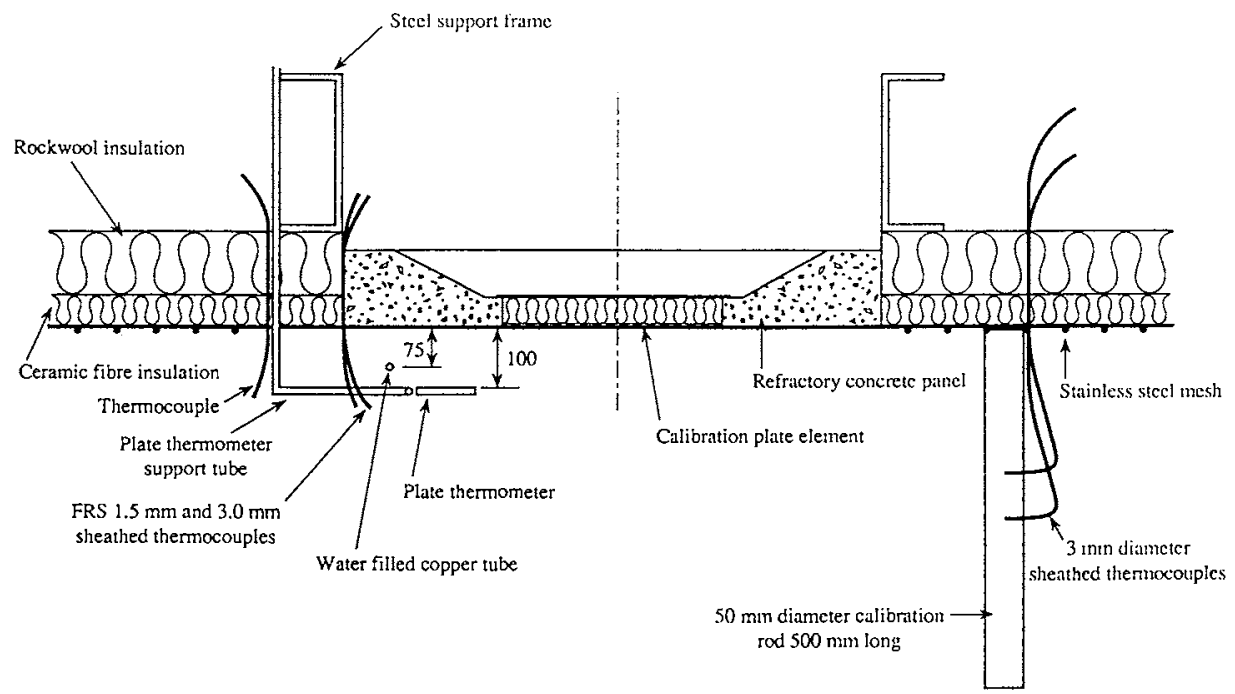

Figure 3 Verticle section through the rig showing positions of calibration elements and temperature sensors

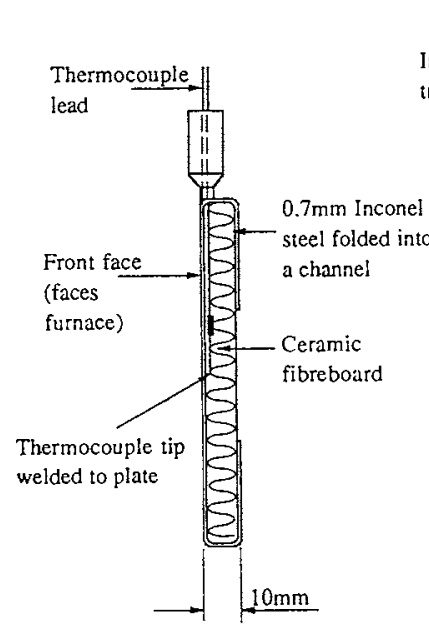

SECTION

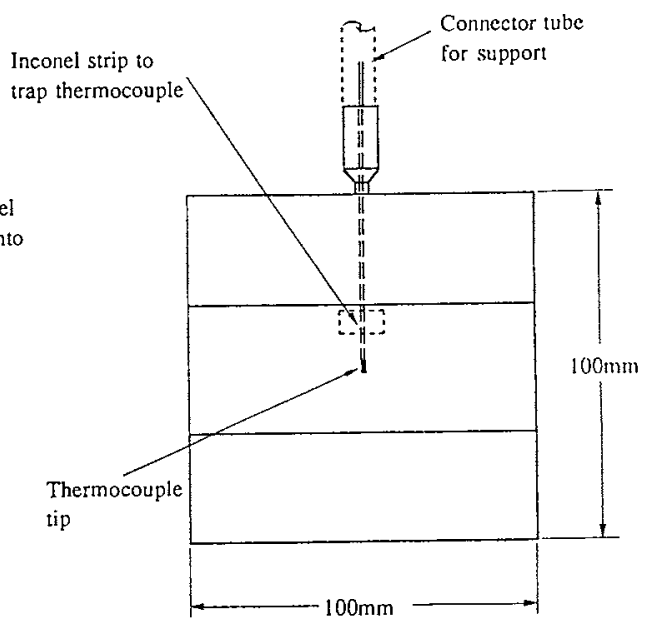

VIEW ON REAR FACE

Figure 4 Details of plate thermometer 


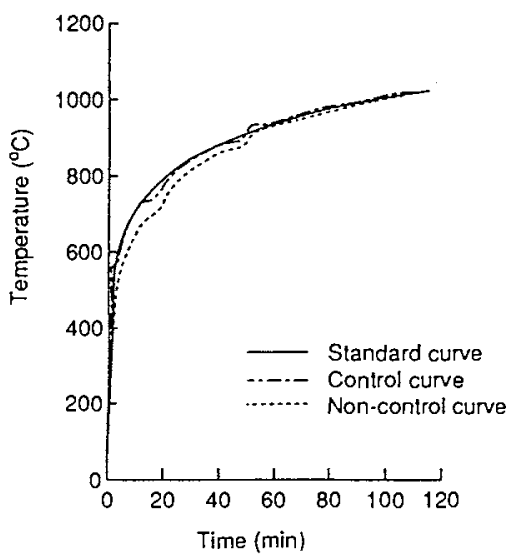

Figure 5 Comparison of ISO 834 curve with WFRC conventional control and non-control temperature-time curves, Test 2

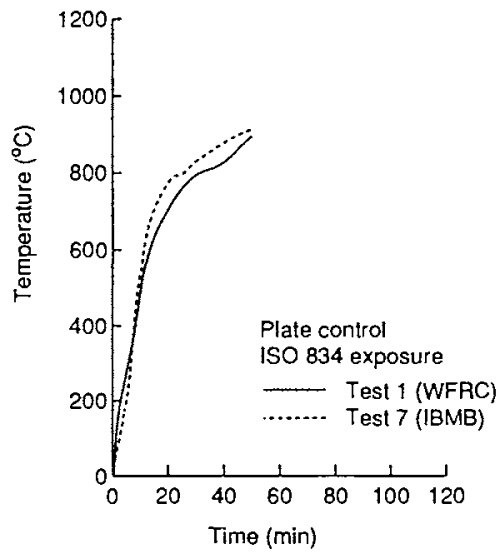

Figure 7 Comparison of average temperature-time curves for calibration plate elements, Test 1 - Test 7

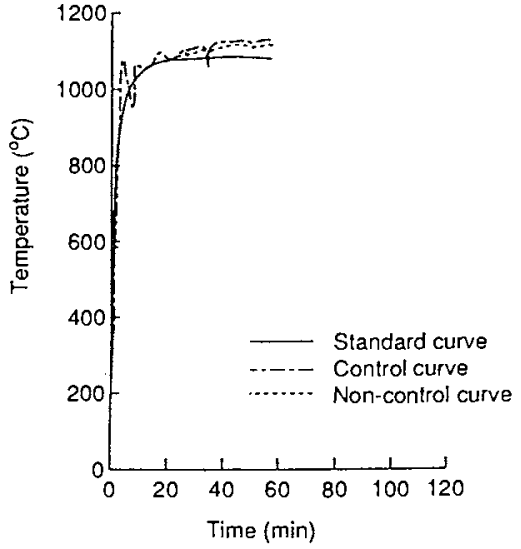

Figure 6 Comparison of NPD curve with IBMB plate control and non-control temperature-time curves, Test 9

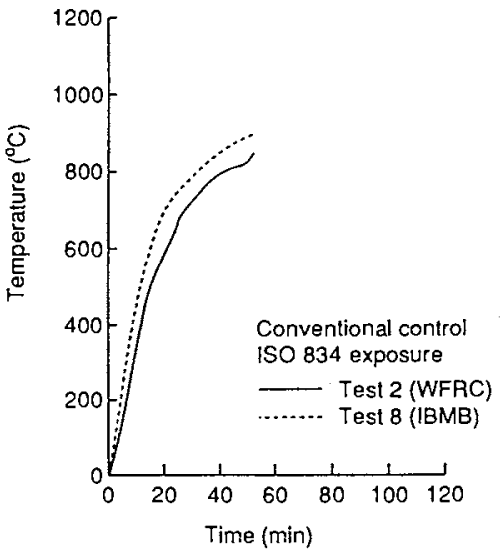

Figure 8 Comparison of average temperature-time curves for calibration plate elements, Test $2 \sim$ Test 8 


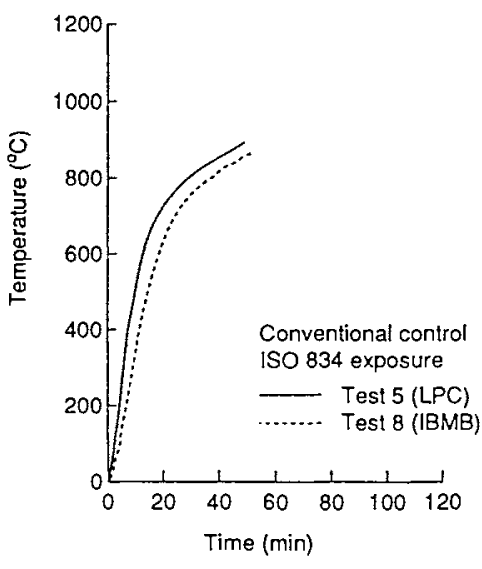

Figure 9 Comparison average of temperature-time curves for calibration plate elements. Test $5 \sim$ Test 8

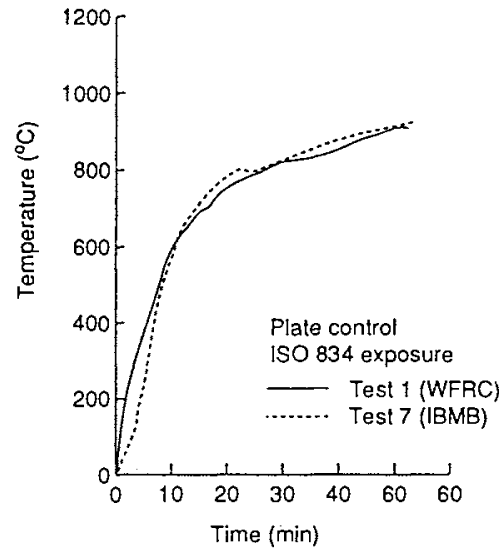

Figure 11 Comparison of temperature-time curves for central calibration plate, Test $1 \sim$ Test 7

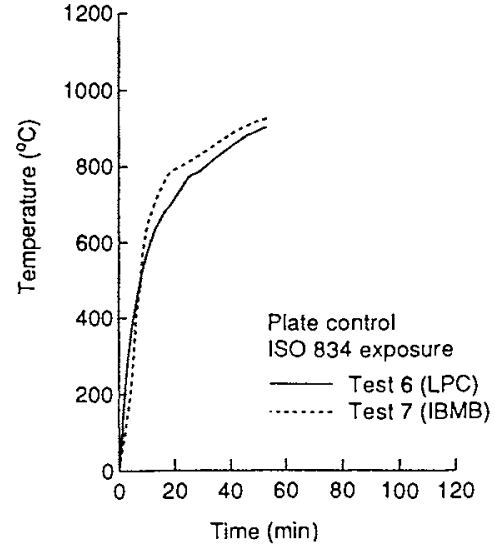

Figure 10 Comparison of average temperature-time curves for calibration plate elements, Test $6 \sim$ Test 7

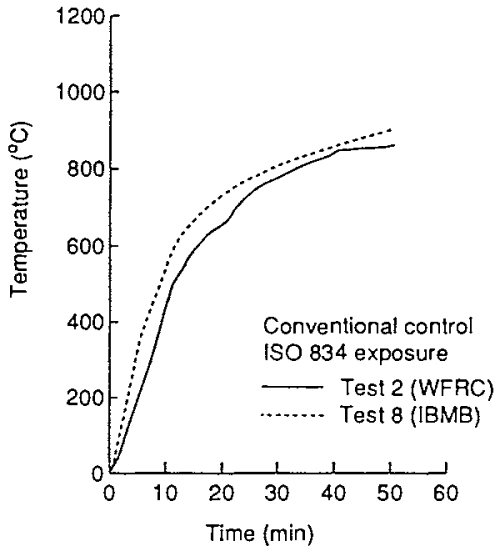

Figure 12 Comparison of temperature-time curves for central calibration plate, Test $2 \sim$ Test 8 


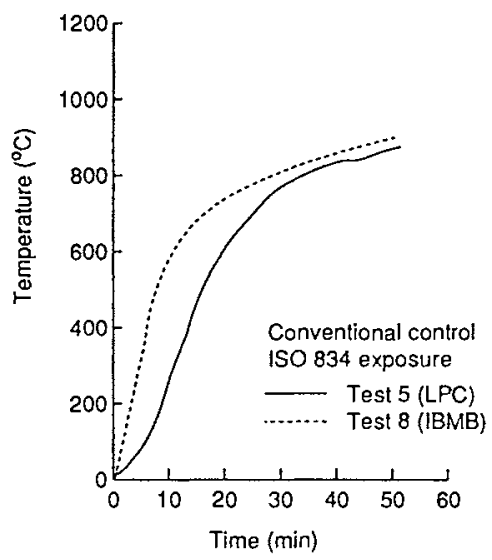

Figure 13 Comparison of temperalure-time curves for central calibration plate, Test $5 \sim$ Test 8

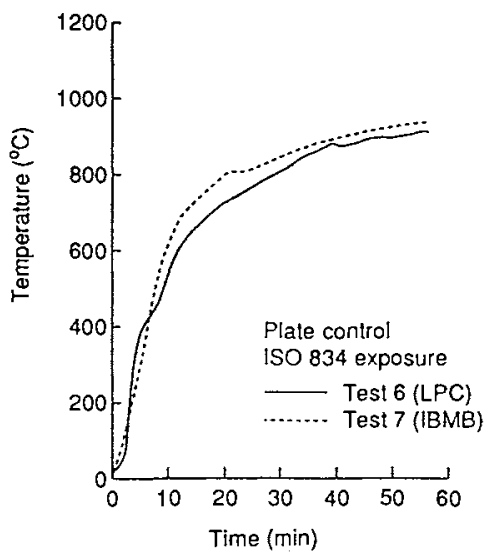

Figure 14 Comparison of temperature-time curves for central calibration plate. Test 6 - Test 7 
